\title{
Proteomic analysis reveals energy metabolic dysfunction and neurogenesis in the prefrontal cortex of a lipopolysaccharide-induced mouse model of depression
}

\author{
ZIYE WANG ${ }^{1-3^{*}}$, WENWEN LI ${ }^{2-4^{*}}$, JIN CHEN ${ }^{2,3,5^{*}}$, HAIYANG SHI ${ }^{2,3,5^{*}}$, MINGJUN ZHAO $^{1-3}$,

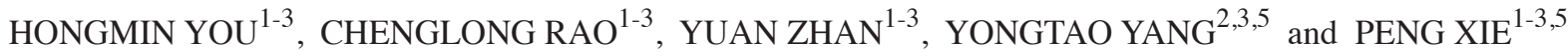 \\ ${ }^{1}$ Department of Neurology, Yongchuan Hospital, Chongqing Medical University, Chongqing 402460; \\ ${ }^{2}$ Chongqing Key Laboratory of Neurobiology; ${ }^{3}$ Institute of Neuroscience and \\ The Collaborative Innovation Center for Brain Science; ${ }^{4}$ Department of Pathology, \\ Faculty of Basic Medicine, Chongqing Medical University; ${ }^{5}$ Department of Neurology, \\ The First Affiliated Hospital of Chongqing Medical University, Chongqing 400016, P.R. China
}

Received October 16, 2014; Accepted September 9, 2015

DOI: $10.3892 / \mathrm{mmr} .2015 .4741$

\begin{abstract}
Substantial evidence from previous studies has suggested an association between major depressive disorder (MDD) and inflammation, and previous studies have associated prefrontal cortex (PFC) dysfunction with MDD. Systemic administration of bacterial lipopolysaccharide has been used to study inflammation-associated behavioral changes in rodents. However, proteomic studies investigating PFC protein expression in an LPS-induced mouse model of depression have yet to be conducted. Using two-dimensional electrophoresis coupled with matrix-assisted laser desorption ionization-time of flight-tandem mass spectrometry, PFC proteomes were comparatively assessed in LPS-induced acute inflammation reaction mice, LPS-induced depressive-like behavior mice (Dep), and control mice. A total of 26 differentially expressed proteins were identified, two of which were selected for western blot analysis, the results of which revealed a significant increase in the expression levels of creatine kinase $B$ and dihydropyrimidinase-like 3 in Dep mice, suggesting that changes in energy metabolism and neurogenesis occur in the PFC of Dep mice. Further investigation on these processes and on the proteins of the PFC are required in order to elucidate the pathophysiological mechanism underlying MDD.
\end{abstract}

Correspondence to: Professor Peng Xie, Department of Neurology, Yongchuan Hospital, Chongqing Medical University, 439 Xuanhua Road, Chongqing 402460, P.R. China

E-mail: xiepeng@cqmu.edu.cn

*Contributed equally

Key words: major depressive disorder, lipopolysaccharide, proteomic, energy metabolic dysfunction, neurogenesis, prefrontal cortex

\section{Introduction}

Major depressive disorder (MDD) is a complex heterogeneous mood disorder, and an estimated one in four women and one in six men are likely to experience depression during their lifetime (1). Previous findings have established a close association between inflammation and depression (2). As compared with euthymic individuals, patients with MDD exhibit an increased inflammatory response (3), and patients with increased inflammatory cytokine levels suffer from increased rates of depression (4). Furthermore, in rodent models, the systemic administration of the pro-inflammatory endotoxin lipopolysaccharide (LPS) triggers depressive-like behavioral alterations (5) and promotes interleukin (IL)-1 $\beta$, IL-6, and tumor necrosis factor $\alpha(\mathrm{TNF}-\alpha)$ inflammatory cytokine production in the brain (6). LPS-induced depressive-like behavior may be observed even after the acute inflammation reaction characteristic of the disease in normalized LPS-treated mice (6). Therefore, increases in inflammatory cytokine levels may be associated with the development of depression (7). However, the mechanisms underlying this phenomenon remain to be elucidated.

A previous study reported that the prefrontal cortex (PFC) has an important role in the pathogenesis of MDD (8). Patients with MDD exhibit gray matter density abnormalities in the right dorsolateral prefrontal cortex (9). Our previous metabolic study demonstrated the presence of amino acid metabolic dysfunction in the PFC of a rodent model of depression (10). Although PFC dysfunction has been associated with the pathophysiology of depression, the association between the PFC and depressive behavior under inflammatory conditions requires further investigation. Therefore, the present study used pro-inflammatory bacterial endotoxin LPS to induce acute an inflammatory reaction and depressive-like behavior in mice to comparatively analyze the PFC proteomes by two-dimensional electrophoresis (2-DE) and matrix-assisted laser desorption ionization-time of flight-tandem mass spectrometry (MALDI-TOF-MS/MS). Western blotting was then used to 
investigate the expression levels of creatine kinase B-type (CKB) and dihydropyrimidinase-related protein 3 (DPYSL3), proteins which are involved in the pathophysiology of MDD.

\section{Materials and methods}

Animals. Male CD-1 mice ( $\mathrm{n}=48$; weight, $35-40 \mathrm{~g}$; age, 10-14 weeks) were obtained from the animal facility at the Chongqing Medical University (Chongqing, China). The animals were housed under standard laboratory conditions (12 h light/dark cycle; temperature, $23 \pm 1^{\circ} \mathrm{C}$; humidity, $45-55 \%$ ), in a single cage with a shelter, and food and water was available ad libitum. The present study was approved by the Ethics Committee of the Chongqing Medical University and all experiments were conducted in accordance with the National Institutes of Health (Bethesda, MD, USA) Guidelines for Animal Research (Guide for the Care and Use of Laboratory Animals).

Drug administration. The mice were randomly divided into three groups: A control group (Con; $n=16)$ treated with $1 \mathrm{mg} / \mathrm{kg}$ sterile saline, an LPS-induced acute inflammatory reaction group (AIR; $\mathrm{n}=16$ ) treated with $0.83 \mathrm{mg} / \mathrm{kg}$ LPS, and an LPS-induced depressive-like behavior group (Dep; $n=16$ ) treated with $0.83 \mathrm{mg} / \mathrm{kg}$ LPS. For the AIR and Dep mice, LPS (L-3129, serotype 055:B5; Sigma-Aldrich, St. Louis, MO, USA) was dissolved in sterile saline and intraperitoneally injected at a dose of $0.83 \mathrm{mg} / \mathrm{kg}$ to induce acute inflammatory reaction (11) and depressive-like behavior (12).

Open-field test (OFT). Prior to experimentation, the mice were placed in the testing room for $30 \mathrm{~min}$ to allow adaptation. The animals were then individually placed in the center of the open field area $(44.5 \times 44.5 \times 45 \mathrm{~cm})$ and after $30 \mathrm{sec}$ adaptation, a 6 min period of free exploration was recorded using a Sony DCR-SR45E digital camera (Sony, Tokyo, Japan). The total distance was recorded during the last $5 \mathrm{~min}$. Following each trial, the apparatus was wiped and cleaned with $80 \%$ alcohol. The videos of the test were analyzed using a Smart video-tracking system (PanLab Harvard Apparatus, Holliston, MA, USA).

Forced swimming test (FST). An FST was conducted as previously described (13) with minor modifications. Briefly, the mice were individually placed into transparent glass cylinders (diameter, $15 \mathrm{~cm}$; height, $30 \mathrm{~cm}$ ) containing $15 \mathrm{~cm}$ of water at $23 \pm 1^{\circ} \mathrm{C}$. Each mouse was required to swim for $6 \mathrm{~min}$, and the total duration of immobility was recorded during the last 5 min of testing. Immobility was defined as the absence of active, escape-oriented behaviors, such as swimming, jumping, rearing, sniffing, or diving (14). The water was replaced with fresh water between each test. Following completion of each test, the mouse was gently removed from the cylinder, dried, and returned to its cage.

Tail suspension test (TST). The TST is one of the most widely-used models for assessing antidepressant-like activity in mice. The test was conducted as previously described (15) with minor modifications. Briefly, each mouse was suspended by its tail using adhesive tape placed $2 \mathrm{~cm}$ from the tip of the tail in an acoustically and visually-isolated suspension box $(22 \times 21 \times 33 \mathrm{~cm})$ for $6 \mathrm{~min}$, and the duration of immobility was recorded during the last $5 \mathrm{~min}$ of testing. The mice were regarded as immobile only when they hung passively or stayed completely motionless.

Protein sample preparation. Our previous studies established a highly effective protein sample preparation protocol $(16,17)$. Briefly, 48 mice $(n=16)$ were decapitated under $100 \%$ diethyl ether [Chongqing Chuandong Chemical (Group) Co., Ltd., Chongqing, China] anesthesia. PFC tissue samples were rapidly dissected from the brain and subsequently frozen in liquid nitrogen. The tissue samples of each experimental group were stored at $-80^{\circ} \mathrm{C}$ until use.

The PFC tissue samples from each experimental group $(n=10)$ were removed from the liquid nitrogen and suspended in $2 \mathrm{ml}$ acetone solution supplemented with $0.2 \%(\mathrm{w} / \mathrm{v})$ dithiothreitol (DTT) and 10\% (w/v) trichloroacetic acid. Following tissue homogenization (Eppendorf, Hamburg, Germany), the cell suspension was incubated at $-20^{\circ} \mathrm{C}$ overnight prior to centrifugation at $35,000 \mathrm{x}$ g for $30 \mathrm{~min}$ at $4^{\circ} \mathrm{C}$. The supernatant was decanted, and the cell pellet was suspended in $2 \mathrm{ml}$ pre-cooled acetone solution supplemented with $0.2 \%(\mathrm{w} / \mathrm{v}) \mathrm{DTT}$, and incubated at $-20^{\circ} \mathrm{C}$ for $1 \mathrm{~h}$, prior to being centrifuged at $35,000 \mathrm{x} \mathrm{g}$ for $30 \mathrm{~min}$ at $4^{\circ} \mathrm{C}$. The supernatant was then decanted, and the cell pellet was dried in a fuming cupboard. Each sample was dissolved in $2 \mathrm{ml} 2$-D lysis buffer (Bio-Rad Laboratories, Inc., Hercules, CA, USA) containing $7 \mathrm{M}$ urea, $2 \mathrm{M}$ thiourea, $4 \%$ CHAPS, $40 \mathrm{mM}$ Tris, $65 \mathrm{mM}$ DTT, $0.3 \mathrm{mg} / \mathrm{ml}$ EDTA, $35 \mu \mathrm{g} / \mathrm{ml}$ phenylmethylsulfonyl fluoride, $0.7 \mu \mathrm{g} / \mathrm{ml}$ pepstatin, $0.5 \mu \mathrm{g} / \mathrm{ml}$ leupeptin, and $0.5 \% \mathrm{v} / \mathrm{v} \mathrm{CA}$, and centrifuged at $40,000 \mathrm{x}$ g for $60 \mathrm{~min}$ at $15^{\circ} \mathrm{C}$. The protein concentration was calculated using a Bradford Protein Assay kit (Bio-Rad Laboratories, Inc.). Bovine serum albumin (Sangon Biotech Co., Ltd., Shanghai, China) was used as a standard control.

2-DE. 2-DE was conducted as previously described (18). Isoelectric focusing (IEF) was performed using $17 \mathrm{~cm}$ ReadyStrip ${ }^{\mathrm{TM}}$ IPG Strips (pH 3-10; Bio-Rad Laboratories, Inc.), and $350 \mu \mathrm{l}$ rehydration buffer containing $0.1 \mathrm{mg}$ protein were loaded onto the strips. Each strip was rehydrated for $12 \mathrm{~h}$ (at $30 \mathrm{~V}$ ) using $350 \mu \mathrm{l}$ rehydration solution containing $7 \mathrm{M}$ urea, $2 \mathrm{M}$ thiourea, 4\% CHAPS, $50 \mathrm{mM}$ DTT, $0.2 \%$ Bio-Lyte, and $0.001 \%$ bromophenol blue (Bio-Rad Laboratories, Inc.) (19). IEF was performed on a Protean IEF cell (Bio-Rad Laboratories, Inc.) as follows: $50 \mathrm{~V}$ for $12 \mathrm{~h}, 250 \mathrm{~V}$ for $30 \mathrm{~min}, 1,000 \mathrm{~V}$ for $1 \mathrm{~h}, 1,000-10,000 \mathrm{~V}$ over a $5 \mathrm{~h}$ step-up period, and 10,000 $\mathrm{V}$ for $6 \mathrm{~h}$. Following IEF, the IPG strips were equilibrated in the reduction buffer containing $0.375 \mathrm{M}$ Tris-HCl (pH 8.8), $6 \mathrm{M}$ urea, $20 \%$ glycerol, and $2 \%$ SDS. The first equilibration was performed using equilibration buffer supplemented with $2 \%$ DTT, and then the second equilibration was performed using equilibration buffer supplemented with $2.5 \%$ indole-3-acetic acid. The second dimension was performed by running the strips on 1 -mm thick $10 \%$ SDS-PAGE using a Protean ${ }^{\circledR}$ IIG xi Multi-Cell (Bio-Rad Laboratories, Inc.). Six gels (three gels per group) were simultaneously run at $12.5 \mathrm{~mA} /$ gel for $30 \mathrm{~min}$ and then $25 \mathrm{~mA} / \mathrm{gel}$ for $5.0-5.5 \mathrm{~h}$ at $20^{\circ} \mathrm{C}$. The protein spots 
A

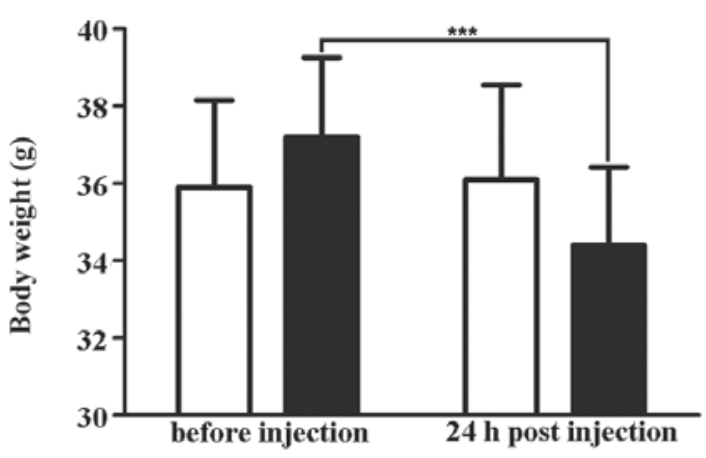

C

TST
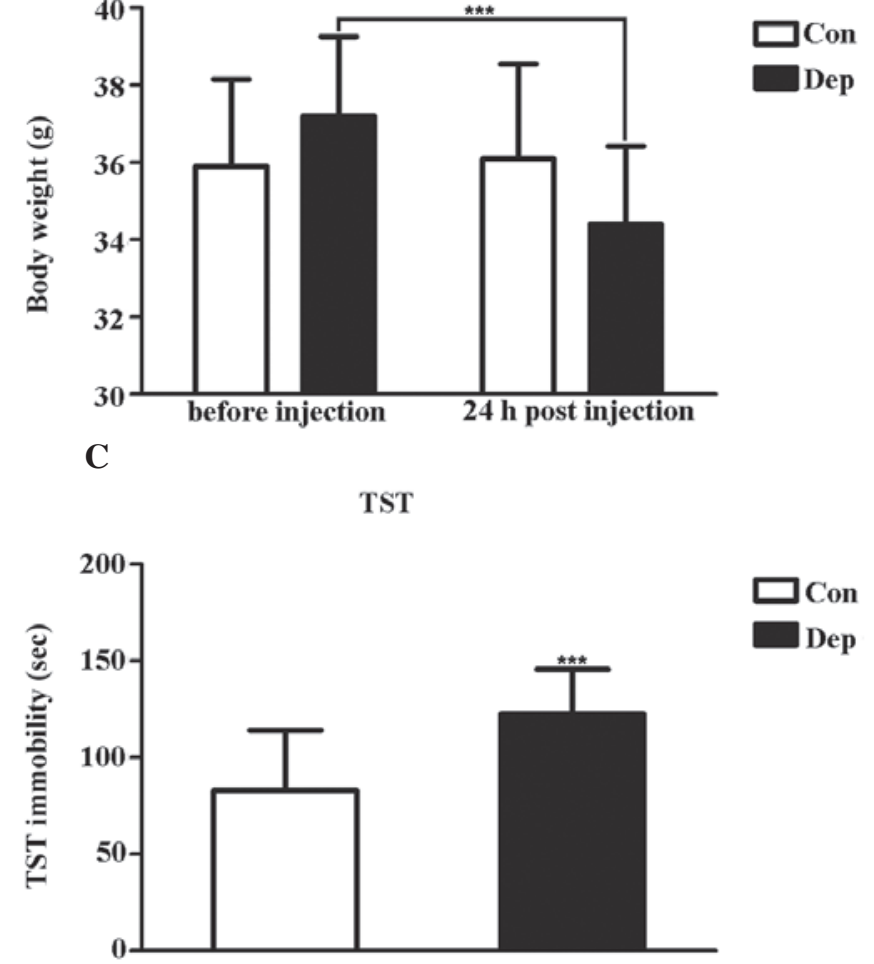

B

D

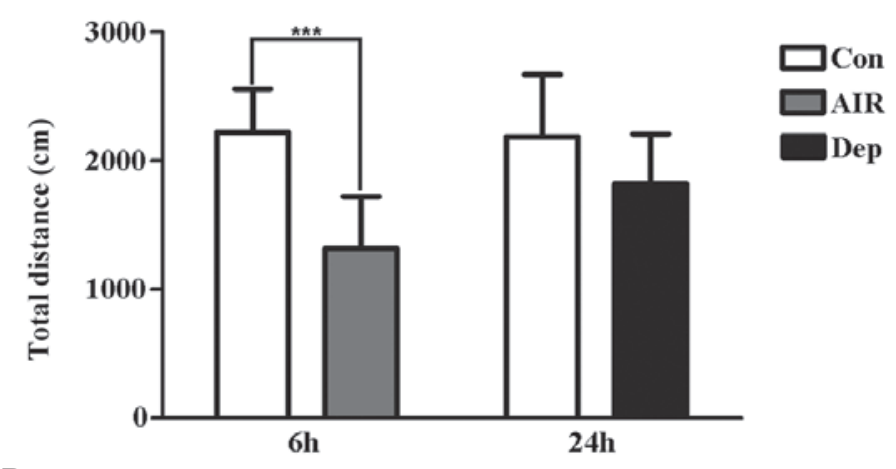

FST

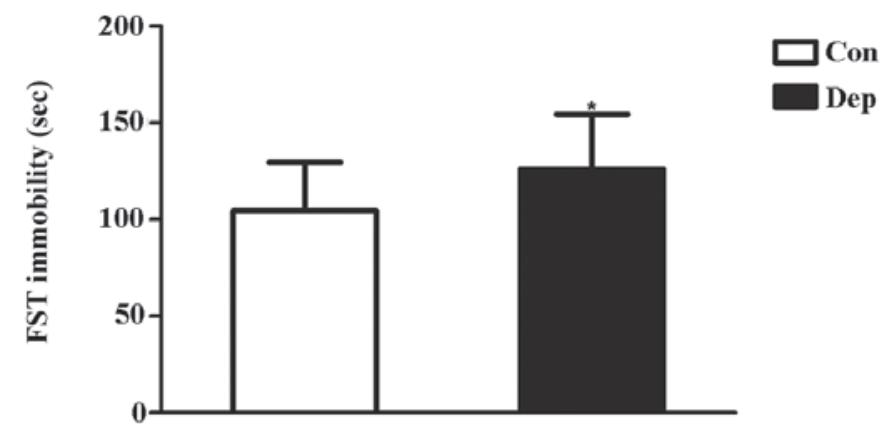

Figure 1. Quality assessment of an LPS-induced mouse model $6 \mathrm{~h}$ and $24 \mathrm{~h}$ post-LPS peritoneal injection. (A) Body weight change, (B) total distance travelled in the OFT, (C) immobility time in the TST, and (D) immobility time in the FST. Data are presented as the mean \pm standard deviation (n=16 subjects per group). "P<0.05, vs. the Con group, and ${ }^{* * *} \mathrm{P}<0.001$. LPS, lipopolysaccharide; OFT, open-field test; TST, tail suspension test; FST, forced swimming test; AIR, LPS-induced acute inflammatory reaction group; Dep, LPS-induced depressive-like behavior group; Con, control group.

were visualized by silver staining as previously described by Yan et al (20).

Gel image analysis. Following visualization, images were scanned using an Epson 10000XL scanner (Epson Co., Ltd. Beijing, China) at an optical resolution of 300 dpi. Image analysis and spot detection were conducted using PDQuest 8.0.1 (Bio-Rad Laboratories, Inc.) with Gaussian spot modeling. For quantitative comparison of the spots across the gels, replicate images of the gels were created. To correct for the variability in silver staining, the individual spot volumes were normalized by dividing the optical density (OD) of each spot value by the sum the total OD of all spots in the respective gels. This method controlled for differences in sample loading and color intensities among the gels. Automated and manual spot matching were also performed. Integrated intensities demonstrating a $\geq 1.5$-fold change were applied to determine the statistical differences in protein expression between the two groups (17).

MALDI-TOF/TOF. Protein samples were separated by 2-DE and visualized with silver staining. In-gel protein digestion was performed as previously described by Zhou et al (21) with minor modifications. The protein spots of interest were excised from the gels and destained. Following reduction and alkylation, the gel sections were digested overnight with Sequencing Grade Modified Trypsin (Promega Corporation, Madison, WI, USA). The digested peptides were extracted using $100 \mu 160 \%$ CAN (Merck Millipore, Darmstadt, Germany) supplemented with $0.1 \%$ TFA (Merck Millipore) and concentrated in a SpeedVac ${ }^{\circledR}$ vacuum concentrator (Thermo Fisher Scientific, Inc., Waltham, MA, USA). The peptides were re-dissolved in a matrix solution and spotted on a MALDI target plate (Applied Biosystems Life Technologies, Foster City, CA, USA). The peptides were then analyzed using the 4800 Plus MALDI TOF/TOF Analyzer (Applied Biosystems Life Technologies) in default mode.

Western blotting. To investigate the differential protein expression in the PFC, two proteins, creatine kinase B-type (CKB) and dihydropyrimidinase-related protein 3 (DPYSL3) were selected for western blotting. $\beta$-tubulin was used as a loading control $(1: 1,000)$. The PFC samples from each group $(n=6)$ were homogenized using a standard lysis buffer containing $50 \mathrm{mM}$ Tris ( $\mathrm{pH} 7.4$ ), $150 \mathrm{mM} \mathrm{NaCl}, 1 \%$ Triton $\mathrm{X}-100,1 \%$ sodium deoxycholate, $0.1 \%$ SDS, sodium orthovanadate, sodium fluoride, EDTA, and leupeptin (Beyotime Institute of Biotechnology, Haimen, China), prior to protein extraction. A bicinchoninic acid assay was used to analyze the protein concentrations. A total of $30 \mu \mathrm{g}$ protein samples were separated by $10 \%$ SDS-PAGE and transferred onto polyvinylidene fluoride membranes. The membranes were blocked using $5 \%(\mathrm{w} / \mathrm{v})$ skimmed milk for $1 \mathrm{~h}$ at room temperature, and then incubated overnight at $4{ }^{\circ} \mathrm{C}$ with anti-CKB rabbit monoclonal antibody (1:3,000; cat. no. ab92452; Abcam, Cambridge, UK) and anti-DPYSL3 rabbit monoclonal antibody (1:1,000; cat. no. ab126787; Abcam). The membranes (Merck Millipore) were washed in Tris-buffered saline with $0.05 \%$ Tween 20 
Table I. Differentially expressed proteins in the prefrontal cortex, as determined by 2-DE and MALDI-TOF-MS/MS.

Fold-change

\begin{tabular}{|c|c|c|c|c|c|c|c|}
\hline \multirow[b]{2}{*}{ Spot no. } & \multirow[b]{2}{*}{ Accession no. } & \multirow[b]{2}{*}{ Gene } & \multirow[b]{2}{*}{ Protein score $(\mathrm{CI} \%)$} & \multirow[b]{2}{*}{ MW (Da) } & \multirow[b]{2}{*}{ PI } & \\
\hline & & & & & & AIR/Con & Dep/Con \\
\hline \multicolumn{8}{|c|}{ Energy metabolism } \\
\hline 1 & Q04447 & $C k b$ & 100 & 42971.4 & 5.4 & 2.19 & 8.24 \\
\hline 2 & P19157 & Gstpl & 100 & 23765.2 & 7.68 & 2.42 & 2.83 \\
\hline 3 & P45376 & $A k r l b 1$ & 100 & 36037.6 & 6.71 & 2.46 & 2.81 \\
\hline 4 & Q9CZ42 & Carkd & 100 & 35651.4 & 8.4 & 2.06 & 1.73 \\
\hline 5 & Q64520 & Gukl & 100 & 22018.3 & 6.12 & 2.52 & 1.58 \\
\hline 6 & Q02053 & Ubal & 100 & 118931.5 & 5.43 & 0.56 & 1.98 \\
\hline 7 & Q9R0Y5 & $A k 1$ & 100 & 21640.2 & 5.67 & 0.65 & 0.44 \\
\hline 8 & P62814 & Atp6v1b2 & 100 & 56874.9 & 5.57 & 0.64 & 0.47 \\
\hline 9 & Q8BMF4 & Dlat & 100 & 68468.9 & 8.81 & 0.41 & 0.56 \\
\hline 10 & P17182 & Enol & 100 & 47453.3 & 6.37 & 0.54 & 0.31 \\
\hline 11 & P05201 & Got1 & 100 & 46488.6 & 6.68 & 0.36 & 0.34 \\
\hline 12 & Q64332 & Syn2 & 100 & 52817.6 & 7.62 & 0.24 & 0.25 \\
\hline \multicolumn{8}{|c|}{ Neurogenesis } \\
\hline 13 & Q3TT92 & Dpysl3 & 100 & 62140.1 & 6.04 & 3.72 & 7 \\
\hline \multicolumn{8}{|c|}{ Cytoskeleton } \\
\hline 14 & P05213 & Tubalb & 100 & 50787.8 & 4.94 & 0.47 & 0.44 \\
\hline 15 & E9Q6X0 & Mapre2 & 100 & 32472.9 & 5.14 & 0.46 & 0.32 \\
\hline 16 & P60710 & $A c t b$ & 100 & 42065.9 & 5.3 & 0.32 & 0.06 \\
\hline \multicolumn{8}{|c|}{ Signal transducer } \\
\hline 17 & Q9DBS2 & Tprgll & 100 & 30023.5 & 6.92 & 1.94 & 2.19 \\
\hline \multicolumn{8}{|c|}{ Redox homeostasis } \\
\hline 18 & Q9D6Y7 & Msra & 100 & 23679.7 & 8.6 & 2.09 & 2.45 \\
\hline 19 & O09131 & Gstol & 100 & 27708 & 6.92 & 1.86 & 2.92 \\
\hline 20 & P08003 & Pdia4 & 100 & 65388.3 & 5.91 & 0.14 & 0.45 \\
\hline \multicolumn{8}{|c|}{ Nuclein metabolism } \\
\hline 21 & P50544 & Acadvl & 100 & 71229.8 & 8.91 & 3.75 & 5.42 \\
\hline 22 & Q80U88 & mKIAA0038 & 100 & 25511.7 & 8.64 & 2.29 & 2.56 \\
\hline 23 & Q8K1M6 & Dnmll & 100 & 83119.7 & 6.61 & 2.31 & 3.97 \\
\hline 24 & Q9Z1S5 & Sept3 & 100 & 38913 & 6.35 & 1.62 & 2.19 \\
\hline 25 & Q8C1B7 & Sept11 & 100 & 49991.4 & 6.14 & 0.44 & 0.51 \\
\hline \multicolumn{8}{|c|}{ Molecular chaperones } \\
\hline 26 & P48722 & Hspa4l & 100 & 95177.8 & 5.54 & 1.76 & 4.86 \\
\hline
\end{tabular}

2-DE, two-dimensional electrophoresis; MALDI-TOF-MS/MS, matrix-assisted laser desorption ionization-time of flight-tandem mass spectrometry; CI, confidence interval; MW, molecular weight; AIR, LPS-induced acute inflammatory reaction group; Dep, LPS-induced depressive-like behavior group; Con, control group; $C k b$, creatine kinase B-type; Gstp1, glutathione S-transferase P1; Akr 1b1, aldose reductase; Carkd, ATP-dependent (S)-NAD(P)H-hydrate dehydratase; Guk1, guanylate kinase; Ubal, ubiquitin-like modifier-activating enzyme 1; $A k 1$, adenylate kinase isoenzyme 1; Atp6v1b2, brain isoform V-type proton ATPase subunit B; Dlat, mitochondrial dihydrolipoyllysine-residue acetyltransferase component of pyruvate dehydrogenase complex; Eno1, $\alpha$-enolase; Got1, cytoplasmic aspartate aminotransferase; Syn2, synapsin-2; Dpysl3, dihydropyrimidinase-related protein 3; Tubalb, tubulin $\alpha-1 \mathrm{~B}$ chain; Mapre2, microtubule-associated protein RP/EB family member 2; Actb, cytoplasmic actin 1; Tprg 11 , tumor protein p63-regulated gene 1-like protein; Msra, mitochondrial peptide methionine sulfoxide reductase; Gsto1, glutathione S-transferase omega-1; Pdia4, protein disulfide-isomerase A4; Acadvl, mitochondrial long-chain specific acyl-CoA dehydrogenase; mKIAA0038, MKIAA0038 protein; Dnm1l, dynamin-1-like protein; Sept3, neuronal-specific septin-3; Sept11, septin-11; Hspa4l, heat shock $70 \mathrm{kDa}$ protein $4 \mathrm{~L}$.

containing $150 \mathrm{mM} \mathrm{NaCl}, 0.05 \%$ Tween 20 , and $10 \mathrm{mM}$ Tris- $\mathrm{HCl}(\mathrm{pH} 7.5)$, and incubated with their respective horseradish peroxidase-conjugated secondary antibodies $(1: 10,000$; Bio-Rad Laboratories, Inc., Hercules, CA, USA) for $2 \mathrm{~h}$ at room temperature. The membranes were visualized using enhanced chemiluminescence and exposed to autoradiography films. Band intensity was determined using Quantity One software (version 4.6.2; Bio-Rad Laboratories, Inc.). 

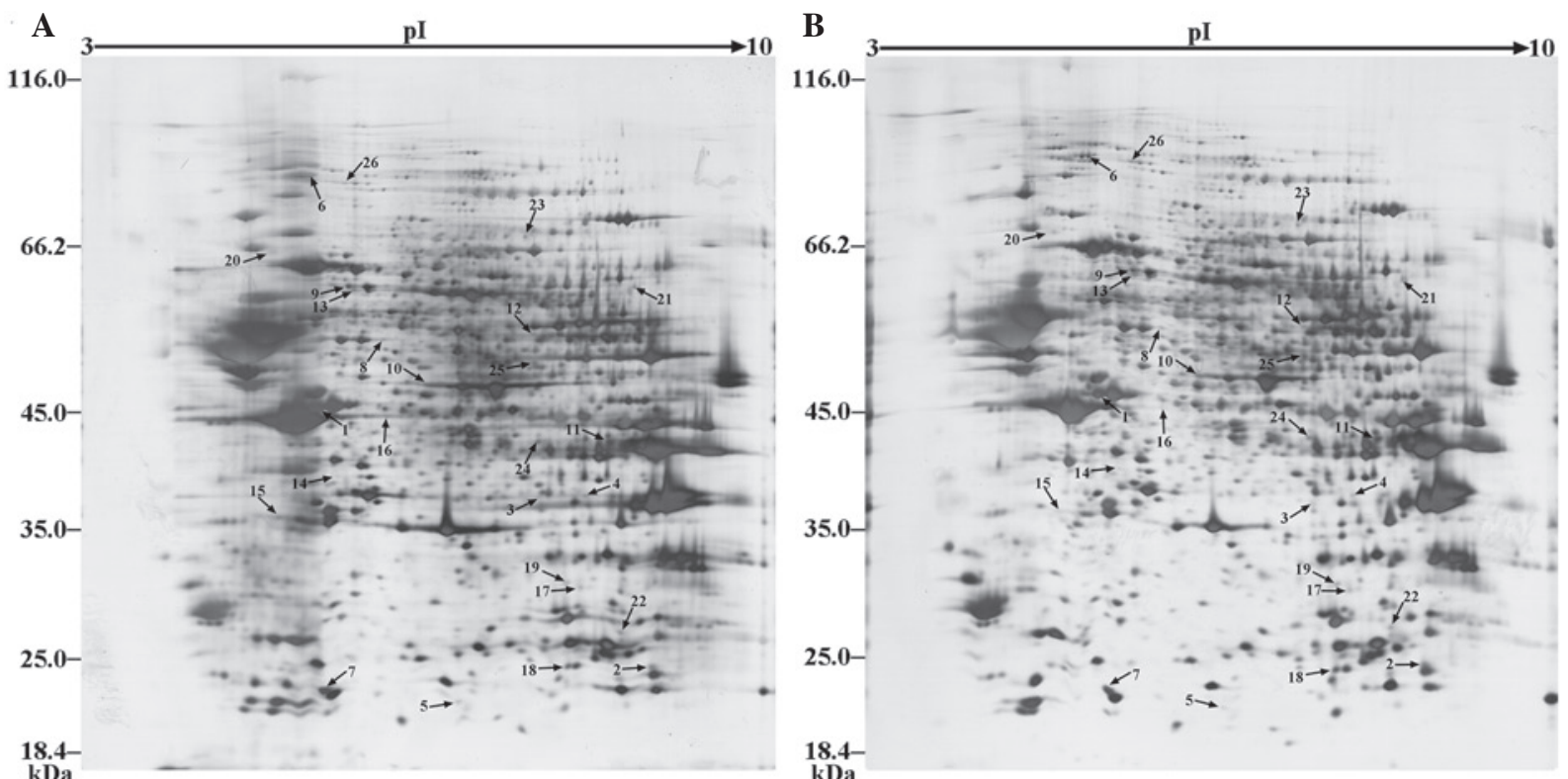

Figure 2. Representative 2-DE gel image of the PFC protein samples. A total of $\sim 1,780$ protein spots in the 3-10 NL range were identified by silver staining. A total of 26 differential spots representing 26 unique differential proteins (numbered with arrows) were identified in the (A) AIR and (B) Dep mice, as compared with the Con mice. 2-DE, two-dimensional electrophoresis; PFC, prefrontal cortex; AIR, LPS-induced acute inflammatory reaction group; Dep, LPS-induced depressive-like behavior group; Con, control group.

A
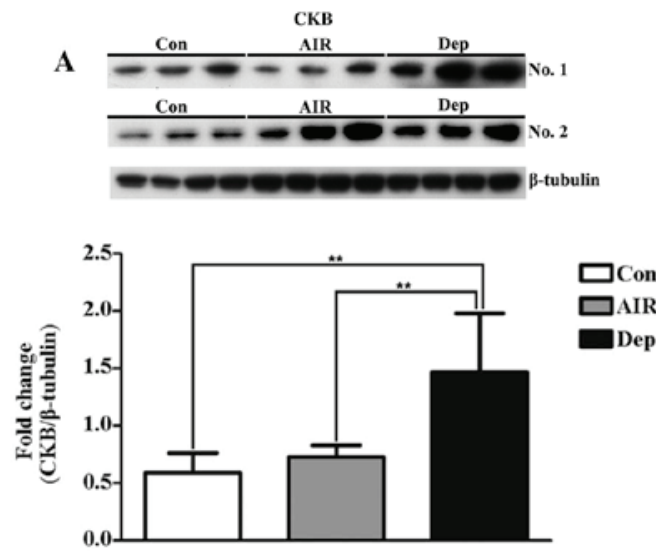

B
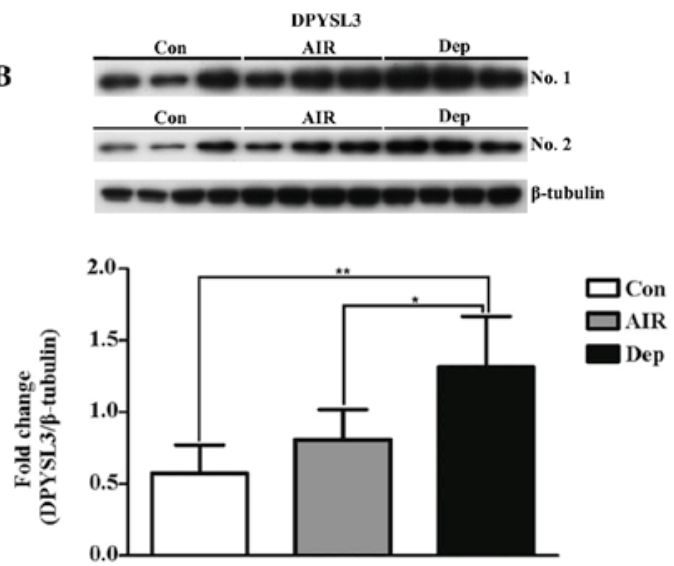

Figure 3. Western blot analysis of (A) CKB and (B) DPYSL3 expression. The expression levels of CKB and DPYSL3 were significantly higher in the Dep group, as compared with the AIR and Con groups. Data are presented as the mean \pm standard deviation ( $\mathrm{n}=6$ subjects per group). ${ }^{*} \mathrm{P}<0.05$, vs. the AIR group, and ${ }^{* *} \mathrm{P}<0.01$. CKB, creatine kinase B-type; DPYSL3, dihydropyrimidinase-related protein ; AIR, LPS-induced acute inflammatory reaction group; Dep, LPS-induced depressive-like behavior group; Con, control group.

Statistical analysis. Statistical analyses were conducted using SPSS 17.0 (SPSS, Inc., Chicago, IL, USA). The results from the western blotting were analyzed using a one-way analysis of variance followed by a Bonferroni's test. Body weight and behavioral test results were compared using the Student's t-tests. $P<0.05$ was considered to indicate a statistically significant difference.

\section{Results}

LPS decrease body weight and mobility. LPS-induced changes in body weight and mobility were measured 6 and $24 \mathrm{~h}$ post-injection by assessing changes in body weight loss and OFT (22). The weights of the Dep mice were significantly reduced, as compared with their weights prior to injection
(Fig. 1A), and the AIR mice exhibited a significant decrease in the total distance travelled in the OFT test, as compared with the control group (Fig. 1B).

The Dep mice exhibited a significant increase in immobility in the TST and FST conducted $24 \mathrm{~h}$ post-LPS injection (Fig. 1C and D). This was the time point when typical acute sickness behavior was no longer apparent (22). These results suggest that acute activation of the peripheral innate immune system by LPS induces depressive-like symptoms in mice that are not biased by acute sickness behaviors.

Differentially expressed protein identification by $2-\mathrm{DE}$ and MALDI-TOF-MS/MS were conducted to examine whether PFC protein expression was altered by LPS. Wide-range $\mathrm{pH}$ 3-10 strips were used to investigate the differential protein expression in the AIR and Dep mice, as compared with the Con 
mice. A total of $\sim 1,780$ protein spots were visualized by silver staining (Fig. 2). To identify the differential proteins in the 2-DE gels, a 1.5-fold change was used as a threshold (Table I). The functional classification of differentially expressed proteins was energy metabolism, neurogenesis, cytoskeleton, signal transducer, redox homeostasis, nuclein metabolism and molecular chaperones (Table I).

Western blot analysis. CKB and DPYSL3 were selected for analysis by western blot analysis. The expression levels of CKB and DPYSL3 were significantly increased in the Dep mice, as compared with the Con and AIR mice (Fig. 3).

\section{Discussion}

Accumulating evidence suggests that inflammation may have an important role in the pathophysiology of MDD. Meta-analysis demonstrated that significantly higher blood expression levels of pro-inflammatory cytokines, such as TNF $\alpha$ and IL-6, were present in drug-free depressive patients, as compared with healthy controls (23). Numerous conditions such as cardiovascular disease (24), type 2 diabetes (25) and obesity (26) are characterized by chronic inflammation and high prevalence of depression. The bacterial endotoxin LPS is widely used in preclinical research as a tool to study neuroinflammation, and numerous studies have identified the mechanisms by which LPS is able to induce inflammatory responses in the brain (27). It is generally accepted that neuroinflammation induces depressive-like behavior in rats (28). In the present study, the systemic administration of LPS resulted in acute inflammatory reaction and depressive-like behavior in CD1 mice. These results suggest that the experimental animals exhibited negative side effects and depressive-like behaviors, such as weight loss, a decrease in the total distance travelled in the OFT, and an increase in immobility time both in the TST and FST. These results were concordant with those of O'Connor et al (22). Based on these results, the LPS-induced model may be established as a reliable animal model of depression, and may be used to better understand the pathophysiological mechanisms underlying depression (29,30).

The present study used a proteomic approach to examine PFC protein expression in an LPS-induced mouse model of depression. A total of 26 proteins were identified that may have roles in the pathogenesis of MDD. Based on the MOTIF database (http://www.genome.jp/tools/motif/) and previous studies (16), a biological function classification on the differentially expressed proteins in the PFC was established. Energy metabolic-associated proteins constitute the majority of the differentially expressed proteins. In a previous study, we demonstrated that energy metabolic signaling pathways were significantly altered in the PFC of a chronic unpredictable mild stress rat model of depression, as determined by KEGG analysis (17). As determined by positron emission tomography of glucose metabolism, energy metabolic dysfunction in the PFC has been associated with depression (31). CKB was one of the energy metabolic-associated proteins of the present study, and is a cytosolic CK of the brain. There are two cytosolic CKs [brain-type CK (CKB), and muscle-type CK (CKM)], and two mitochondrial CKs [ubiquitous mitochondrial CK (uMtCK) and muscle-specific sarcomeric mtCK] (32). CKs regulate
ATP regeneration via the transfer of high-energy phosphate from create phosphocreatine to adenosine diphosphate $(33,34)$. The phosphocreatine/CK energy circuit is important for the maintenance of normal energy homeostasis $(35,36)$, and has a number of integrated functions, such as temporary energy buffering and energy transfer, as well as regulating metabolic capacity (37). The results from the western blot analysis indicated that the expression levels of CKB were significantly elevated in the Dep mice, suggesting that LPS-induced depressive-like behaviors in mice may be associated with changes in the energy metabolism of the PFC.

In 2000, a previous study proposed for the first time a neurogenic theory of depression, and demonstrated that impaired adult hippocampal neurogenesis (AHN) triggers depression, and restoration of $\mathrm{AHN}$ lead to the alleviation of depressive symptoms (38). Previously, we reported that alterations in hippocampal neurogenesis may have a role in mediating the pathogenesis of depression (16). However, to the best of our knowledge, few studies have investigated neurogenesis in the PFC. The results of the present study demonstrated that DPYSL3, which is a neurogenesis-associated protein, was one of the differentially expressed proteins of the PFC. DPYSL3 is also known as collapsin response mediator protein 4 (CRMP4), which belongs to the cytosolic phosphoprotein family, and is involved in neurite and axonal outgrowth (39-42), neuronal differentiation $(39,43,44)$, axonal guidance (45) and regeneration (46). Previous studies demonstrated that DPYS13 interacts with cytoskeletal proteins tubulin and actin, suggesting DPYS13 is involved in cell assembly and migration $(40,47)$. DPYS13 is also involved in developmental neurogenesis, neuroregeneration following nerve lesion, and growth cone collapse during neuronal cell injury, by organizing filamentous actin into tight bundles $(43,46,48)$. Immunocytochemistry revealed that CRMP-4 is transiently expressed in post-mitotic neurons during rat brain development (49). Therefore, DPYSL3 was selected for further investigation. The results of the present study demonstrate that the expression levels of DPYSL3 were significantly elevated in the Dep mice, suggesting that LPS-induced depressive-like behavior in mice may be associated with changes in neurogenesis in the PFC.

In conclusion, the present study has demonstrated that LPS is able to induce depressive-like behavior independently of changes in motor activity. Using a 2-DE-MALDI-TOF-MS/ MS-based proteomic approach, 26 differentially expressed proteins were identified in the PFC of the Dep mice, as compared with the Con mice. The expression levels of CKB and DPYSL3 were significantly elevated in the Dep mice, as determined by western blotting. These results suggest that energy metabolic dysfunction and neurogenesis are significantly altered in the PFC of Dep mice. Investigation into these processes and proteins in the PFC is crucial to obtain a further understanding of the pathophysiological mechanisms underlying MDD.

\section{Acknowledgements}

The authors would like to thank Dr N.D. Melgiri for editing and proofreading the manuscript of the present study, as well as Jack Cheng (Chongqing Medical University). The present study was supported by a grant from the National Basic Research Program of China (973 program; grant no. 2009CB918300). 


\section{References}

1. Kessler RC, Birnbaum H, Bromet E, Hwang I, Sampson N and Shahly V: Age differences in major depression: Results from the National Comorbidity Survey Replication (NCS-R). Psychol Med 40: 225-237, 2010

2. Raison CL, Capuron L and Miller AH: Cytokines sing the blues: Inflammation and the pathogenesis of depression. Trends Immunol 27: 24-31, 2006.

3. Zorrilla EP, Luborsky L, McKay JR, Rosenthal R, Houldin A, Tax A, McCorkle R, Seligman DA and Schmidt K: The relationship of depression and stressors to immunological assays: A meta-analytic review. Brain Behav Immun 15: 199-226, 2001.

4. Yirmiya R, Pollak Y, Morag M, Reichenberg A, Barak O, Avitsur R, Shavit Y, Ovadia H, Weidenfeld J, Morag A, et al: Illness, cytokines, and depression. Ann NY Acad Sci 917: 478-487, 2000.

5. Dantzer R, O'Connor JC, Freund GG, Johnson RW and Kelley KW: From inflammation to sickness and depression: When the immune system subjugates the brain. Nat Rev Neurosci 9: 46-56, 2008.

6. Frenois F, Moreau M, O'Connor J, Lawson M, Micon C, Lestage J, Kelley KW, Dantzer R and Castanon N: Lipopolysaccharide induces delayed FosB/DeltaFosB immunostaining within the mouse extended amygdala, hippocampus and hypothalamus, that parallel the expression of depressive-like behavior. Psychoneuroendocrinology 32: 516-531, 2007.

7. Hannestad J, DellaGioia N and Bloch M: The effect of antidepressant medication treatment on serum levels of inflammatory cytokines: A meta-analysis. Neuropsychopharmacology 36: 2452-2459, 2011.

8. Koenigs $\mathrm{M}$ and Grafman J: The functional neuroanatomy of depression: Distinct roles for ventromedial and dorsolateral prefrontal cortex. Behav Brain Res 201: 239-243, 2009.

9. Ye T, Peng J, Nie B, Gao J, Liu J, Li Y, Wang G, Ma X, Li K and Shan B: Altered functional connectivity of the dorsolateral prefrontal cortex in first-episode patients with major depressive disorder. Eur J Radiol 81: 4035-4040, 2012.

10. Chen G, Yang D, Yang Y, Li J, Cheng K, Tang G, Zhang R, Zhou J, Li W, Liu Z, Fan S and Xie P: Amino acid metabolic dysfunction revealed in the prefrontal cortex of a rat model of depression. Behav Brain Res 278: 286-292, 2015.

11. Mormède C, Palin K, Kelley KW, Castanon N and Dantzer R: Conditioned taste aversion with lipopolysaccharide and peptidoglycan does not activate cytokine gene expression in the spleen and hypothalamus of mice. Brain Behav Immun 18: 186-200, 2004.

12. Lestage J, Verrier D, Palin K and Dantzer R: The enzyme indoleamine 2,3-dioxygenase is induced in the mouse brain in response to peripheral administration of lipopolysaccharide and superantigen. Brain Behav Immun 16: 596-601, 2002.

13. Porsolt RD, Bertin A and Jalfre M: Behavioral despair in mice: A primary screening test for antidepressants. Arch Int Pharmacodyn Ther 229: 327-336, 1977.

14. Porsolt RD, Anton G, Blavet N and Jalfre M: Behavioural despai in rats: A new model sensitive to antidepressant treatments. Eur J Pharmacol 47: 379-391, 1978.

15. Steru L, Chermat R, Thierry B and Simon P: The tail suspension test: A new method for screening antidepressants in mice. Psychopharmacology (Berl) 85: 367-370, 1985.

16. Mu J, Xie P, Yang ZS, Yang DL, Lv FJ, Luo TY and Li Y: Neurogenesis and major depression: Implications from proteomic analyses of hippocampal proteins in a rat depression model. Neurosci Lett 416: 252-256, 2007.

17. Yang Y, Yang D, Tang G, Zhou C, Cheng K, Zhou J, Wu B, Peng Y, Liu C, Zhan Y, et al: Proteomics reveals energy and glutathione metabolic dysregulation in the prefrontal cortex of a rat model of depression. Neuroscience 247: 191-200, 2013.

18. Hu Y, Zhou J, Fang L, Liu H, Zhan Q, Luo D, Zhou C, Chen J, Li Q and Xie P: Hippocampal synaptic dysregulation of exo/endocytosis-associated proteins induced in a chronic mild-stressed rat model. Neuroscience 230: 1-12, 2013.

19. Hwang YY and Li MD: Proteins differentially expressed in response to nicotine in five rat brain regions: Identification using a 2-DE/MS-based proteomics approach. Proteomics 6: 3138-3153, 2006.

20. Yan JX, Wait R, Berkelman T, Harry RA, Westbrook JA, Wheeler $\mathrm{CH}$ and Dunn MJ: A modified silver staining protocol for visualization of proteins compatible with matrix-assisted laser desorption/ionization and electrospray ionization-mass spectrometry. Electrophoresis 21: 3666-3672, 2000.
21. Zhou J, Xiong J, Li J, Huang S, Zhang H, He Q, Lin Y, Chen P, Wang X and Liang S: Gel absorption-based sample preparation for the analysis of membrane proteome by mass spectrometry. Anal Biochem 404: 204-210, 2010.

22. O'Connor JC, Lawson MA, André C, Moreau M, Lestage J, Castanon N, Kelley KW and Dantzer R: Lipopolysaccharide-induced depressive-like behavior is mediated by indoleamine 2,3-dioxygenase activation in mice. Mol Psychiatry 14: 511-522, 2009.

23. Dowlati Y, Herrmann N, Swardfager W, Liu H, Sham L, Reim EK and Lanctôt KL: A meta-analysis of cytokines in major depression. Biol Psychiatry 67: 446-457, 2010.

24. Celano CM and Huffman JC: Depression and cardiac disease: A review. Cardiology (in review).

25. Alexandraki K, Piperi C, Kalofoutis C, Singh J, Alaveras A and Kalofoutis A: Inflammatory process in type 2 diabetes: The role of cytokines. Ann NY Acad Sci 1084: 89-117, 2006.

26. Capuron L, Poitou C, Machaux-Tholliez D,Frochot V, Bouillot JL, Basdevant A, Layé S and Clément K: Relationship between adiposity, emotional status and eating behaviour in obese women: Role of inflammation. Psychol Med 41: 1517-1528, 2011.

27. Kellom M, Basselin M, Keleshian VL, Chen M, Rapoport SI and Rao JS: Dose-dependent changes in neuroinflammatory and arachidonic acid cascade markers with synaptic marker loss in rat lipopolysaccharide infusion model of neuroinflammation. BMC Neurosci 13: 50, 2012.

28. Hurley LL and Tizabi Y: Neuroinflammation, neurodegeneration, and depression. Neurotox Res 23: 131-144, 2013.

29. Ji WW, Wang SY, Ma ZQ, Li RP, Li SS, Xue JS, Li W, Niu XX, Yan L, Zhang X, et al: Effects of perillaldehyde on alternations in serum cytokines and depressive-like behavior in mice after lipopolysaccharide administration. Pharmacol Biochem Behav 116: 1-8, 2014

30. Lawson MA, Parrott JM, McCusker RH, Dantzer R, Kelley KW and O'Connor JC: Intracerebroventricular administration of lipopolysaccharide induces indoleamine-2,3-dioxygenase-dependent depression-like behaviors. J Neuroinflammation 10: 87, 2013.

31. Reininghaus EZ, Reininghaus B, Ille R, Fitz W, Lassnig RM, Ebner C, Annamaria P, Hofmann P, Kapfhammer HP, Reingard A, et al: Clinical effects of electroconvulsive therapy in severe depression and concomitant changes in cerebral glucose metabolism - an exploratory study. J Affect Disord 146: 290-294, 2013

32. Wyss $M$ and Kaddurah-Daouk R: Creatine and creatinine metabolism. Physiol Rev 80: 1107-1213, 2000.

33. Wallimann T, Walzthöny D, Wegmann G, Moser H, Eppenberger HM and Barrantes FJ: Subcellular localization of creatine kinase in Torpedo electrocytes: Association with acetylcholine receptor-rich membranes. J Cell Biol 100: 1063-1072, 1985

34. Wallimann T: Bioenergetics. Dissecting the role of creatine kinase. Curr Biol 4: 42-46, 1994.

35. Khuchua ZA, Qin W, Boero J, Cheng J, Payne RM, Saks VA and Strauss AW: Octamer formation and coupling of cardiac sarcomeric mitochondrial creatine kinase are mediated by charged N-terminal residues. J Biol Chem 273: 22990-22996, 1998 .

36. Schlattner U and Wallimann T: Octamers of mitochondrial creatine kinase isoenzymes differ in stability and membrane binding. J Biol Chem 275: 17314-17320, 2000.

37. Saks VA, Kuznetsov AV, Kupriyanov VV, Miceli MV and Jacobus WE: Creatine kinase of rat heart mitochondria. The demonstration of functional coupling to oxidative phosphorylation in an inner membrane-matrix preparation. J Biol Chem 260: 7757-7764, 1985

38. Jacobs BL, van Praag H and Gage FH: Adult brain neurogenesis and psychiatry: A novel theory of depression. Mol Psychiatry 5: 262-269, 2000.

39. Charrier E, Reibel S, Rogemond V, Aguera M, Thomasset $\mathrm{N}$ and Honnorat $\mathrm{J}$ : Collapsin response mediator proteins (CRMPs): Involvement in nervous system development and adult neurodegenerative disorders. Mol Neurobiol 28: 51-64, 2003.

40. Rosslenbroich V, Dai L, Baader SL, Noegel AA, Gieselmann V and Kappler J: Collapsin response mediator protein-4 regulates F-actin bundling. Exp Cell Res 310: 434-444, 2005.

41. Schmidt EF and Strittmatter SM: The CRMP family of proteins and their role in Sema3A signaling. Adv Exp Med Biol 600: 1-11, 2007. 
42. Alabed YZ, Pool M, Ong Tone S, Sutherland C and Fournier AE: GSK3 beta regulates myelin-dependent axon outgrowth inhibition through CRMP4. J Neurosci 30: 5635-5643, 2010.

43. Goshima Y, Nakamura F, Strittmatter P and Strittmatter SM: Collapsin-induced growth cone collapse mediated by an intracellular protein related to UNC-33. Nature 376: 509-514, 1995.

44. Gaetano C, Matsuo T and Thiele CJ: Identification and characterization of a retinoic acid-regulated human homologue of the unc-33-like phosphoprotein gene (hUlip) from neuroblastoma cells. J Biol Chem 272: 12195-12201, 1997.

45. Byk T, Dobransky T, Cifuentes-Diaz C and Sobel A: Identification and molecular characterization of Unc-33-like phosphoprotein (Ulip), a putative mammalian homolog of the axonal guidance-associated unc-33 gene product. J Neurosci 16: 688-701, 1996
46. Minturn JE, Fryer HJ, Geschwind DH and Hockfield S: TOAD-64, a gene expressed early in neuronal differentiation in the rat, is related to unc-33, a C. elegans gene involved in axon outgrowth. J Neurosci 15: 6757-6766, 1995.

47. Franken S, Junghans U, Rosslenbroich V, Baader SL, Hoffmann R, Gieselmann V, Viebahn C and Kappler J: Collapsin response mediator proteins of neonatal rat brain interact with chondroitin sulfate. J Biol Chem 278: 3241-3250, 2003.

48. Yuasa-Kawada J, Suzuki R, Kano F, Ohkawara T, Murata M and Noda M: Axonal morphogenesis controlled by antagonistic roles of two CRMP subtypes in microtubule organization. Eur J Neurosci 17: 2329-2343, 2003.

49. Minturn JE, Geschwind DH, Fryer HJ and Hockfield S: Early postmitotic neurons transiently express TOAD-64, a neural specific protein. J Comp Neurol 355: 369-379, 1995. 